\title{
Green Tea-Derived Theabrownin Induces Cellular Senescence and Apoptosis of Hepatocellular Carcinoma via P53 Signaling-Mediated Mechanism Bypassed by JNK Regulation
}

Jiaan Xu

College of Pharmaceutical Sciences, Zhejiang Chinese Medical University

Bo Yan

College of Pharmaceutical Sciences, Zhejiang Chinese Medical University

\section{Xiujuan Xiao}

College of Pharmaceutical Sciences, Zhejiang Chinese Medical University

\section{Qiang Yuan}

College of Pharmaceutical Sciences, Zhejiang Chinese Medical University

\section{Xiaoqiao Dong}

Zhejiang University School of Medicine Affiliated First People's Hospital

\section{Quan Du}

Zhejiang University School of Medicine Affiliated First People's Hospital

\section{Jin Zhang}

Theabio Co., Ltd

Letian Shan ( $\square$ letian.shan@zcmu.edu.cn )

Zhejiang Chinese Medical University https://orcid.org/0000-0003-4926-0527

\section{Zhishan Ding}

College of Pharmaceutical Sciences, Zhejiang Chinese Medical University

\section{Li Zhou}

Zhejiang Chinese Medical University Affiliated First Hospital

\section{Thomas Efferth}

Institution of Pharmacy and Biochemistry, Johannes Gutenberg University

\section{Primary research}

Keywords: theabrownin, hepatocellular carcinoma, cellular senescence, apoptosis, p53, JNK, SK-Hep-1

Posted Date: November 9th, 2021

DOI: https://doi.org/10.21203/rs.3.rs-1049721/v1 
License: (c) (i) This work is licensed under a Creative Commons Attribution 4.0 International License. Read Full License 


\section{Abstract}

Background: Theabrownin (TB) is a bioactive component of tea and has been reported to exert effects against many human cancers, but its efficacy and mechanism on hepatocellular carcinoma (HCC) with different p53 genotypes remains unclarified.

Methods: MTT assay, DAPI staining, flow cytometry and SA- $\beta$-gal staining were applied to evaluate the effects of TB on HCC cells. Quantitative real time PCR (qPCR) and Western blot (WB) were conducted to explore the molecular mechanism of TB. And xenograft model of zebrafish was established to evaluate the anti-tumor effect of TB.

Results: MTT assays showed that TB significantly inhibited the proliferation of SK-Hep-1, HepG2, and Huh7 cells in a dose-dependent manner, of which SK-Hep-1 was the most sensitive one with the lowest $\mathrm{IC}_{50}$ values. The animal data showed that TB remarkably suppressed SK-Hep-1 tumor growth in xenograft model of zebrafish. The cellular data showed TB's pro-apoptotic and pro-senescent effect on SK-Hep-1 cells. The molecular results revealed the mechanism of TB that p53 signaling pathway (p-ATM, p-ATR, $\mathrm{Y}^{-}$ $\mathrm{H} 2 \mathrm{AX}, \mathrm{p}-\mathrm{Chk2}$, and p-p53) was activated with up-regulation of downstream senescent genes (P16, P21, IL6 and $I L-8)$ as well as apoptotic genes (Bim, Bax and PUMA) and proteins (Bax, c-Casp9 and c-PARP). The p53-mediated mechanism was verified by using p53-siRNA. Moreover, by using JNK-siRNA, we found JNK as a bypass regulator in TB's mechanism.

Conclusions: To sum up, TB exerted tumor-inhibitory, pro-senescent and pro-apoptotic effects on SK-Hep1 cells through ATM-Chk2-p53 signaling axis in accompany with JNK bypass regulation. This is the first report on the pro-senescent effect and multi-target (p53 and JNK) mechanism of TB on HCC cells, providing new insights into the underlying mechanisms of TB's anti-HCC efficacy.

\section{Introduction}

Liver cancer is a major contributor to the world's cancer burden, with more than 800,000 new cases and 700,000 death each year ${ }^{[1]}$. Hepatocellular carcinoma (HCC), a principal histologic type of liver cancer, represents more than $75 \%$ of primary liver cancers ${ }^{[2]}$. Due to the aging and population growth, the global incidence of HCC increased by 75\% between 1990 and 2015, with the highest incident, mortality and years of life lost in east $\mathrm{Asia}^{[3]}$. The worldwide risk factors of $\mathrm{HCC}$ is heterogeneous. Hepatitis $\mathrm{B}$ virus (HBV) is the leading cause of incident cases of HCC in Africa and East Asia, while alcoholic liver disease (ALD) and hepatitis $\mathrm{C}(\mathrm{HCV})$ are the most common risk factor for HCC in the USA $A^{[4]}$. Prognosis of HCC is poor all around the world, resulting in a rough equivalent of incidence and mortality rates ${ }^{[5]}$. For earlystage $\mathrm{HCC}$, radiofrequency ablation or surgical resection remains the main treatment. However, up to $75 \%$ of patients undergoing surgery experience recurrence within 5 years ${ }^{[6]}$. Over the last decade, targeted therapy (sorafenib) has become the major systemic strategy which can significantly improve the overall survival for patients with unresectable HCC ${ }^{[7]}$. However, the adverse effects of sorafenib, such as diarrhea, 
hypertension, and hand-foot skin reaction (HFSR), as well as its low bioavailability limit its clinical application ${ }^{[8,9]}$. Therefore, there is an urgent need to explore potential drug candidates for HCC.

Alike many carcinomas, $\mathrm{HCC}$ has multiple genomic mutations. The prevalent mutations locate at TERT promoters, such as TP53, CTNNB1, AXIN1 and CDKN2A ${ }^{[10,11]}$. In most cases of $\mathrm{HCC}(>90 \%)$, telomerase activation, relating to TERT promoter mutations, is necessary for malignant transformation and tumor progression ${ }^{[12,13]}$. Of these, CTNNB1 mutations frequently activate the $\mathrm{Wnt} / \beta$-catenin pathway, particularly in patients with HBV uninfection and well-differentiated tumors $\left(11-37 \%\right.$ of HCC cases) ${ }^{[14}$, 15]. By contrast, inactivation of p53 caused by TP53 mutations particularly appears in cases related to HBV infection and aflatoxin B1 exposure ${ }^{[16-18]}$. As a tumor suppressor, TP53 encodes p53 transcriptional factor to prevent tumor development through permanently suppression of cell proliferation by cell cycle arrest and facilitation of cell death by apoptosis ${ }^{[19]}$. However, TP53 mutation or deletion occurs in nearly a half of human cancers, while tumors carrying wild-type TP53 usually get rid of the p53 defense mechanism via interaction with negative regulators, such as MDM2 and MDM4 ${ }^{[20,21]}$. Thus, reactivation of p53 becomes a potential strategy for cancer treatment ${ }^{[22-25]}$ For instance, a p53-MDM2 inhibitor, RG7388, activates p53 signaling pathway by selectively blocking p53-MDM2 binding, exhibiting encouraging anti-cancer efficacy in several different clinical trials ${ }^{[26,27]}$.

Green tea, derived from leaves of Camellia sinensis, was originally used as medicine in ancient China. Meanwhile, it was one of the most prevalent beverages worldwide for centuries. In recent decades, green tea's health benefits have been extensively studied, including anti-inflammation, cardiovascularprotection, anti-obesity, anti-cancer, and hepato-protection ${ }^{[28-32]}$. A large prospective cohort study on 164681 adult Chinese men has concluded that $10 \mathrm{~g}$ or more green tea consumption per day decreased the mortality from cancers, indicating an anti-cancer efficacy of green tea ${ }^{[33]}$. As the main pigment of tea, theabrownin (TB) possesses regulatory effects in improving metabolism of glucose and serum lipids ${ }^{[34-}$ 36]. Our previous studies have discovered TB's pro-apoptotic effects on human carcinoma cells and sarcoma cells both through a p53-mediated mechanism ${ }^{[37,38]}$. To date, the efficacy of TB on human HCC cells with different p53 genotypes remains unclear. To fill this gap, this study adopted HCC cell lines, including SK-Hep-1 (p53-WT), HepG2 (p53-WT) and Huh7 (p53-mut), to evaluate TB囚s effects and the p53-related mechanism.

\section{Materials And Methods}

\section{Chemicals and reagents}

Theabrownin ( $>90 \%$ of purity) was supplied by Theabio Co., Ltd (Hangzhou, China) (Batch number: 20181210001). Fetal bovine serum (FBS), 0.25\% trypsin Dulbecco's modified eagle medium (DMEM) and Minimum Essential Medium a (MEM a), were obtained from Thermo Fisher Scientific (MA, USA). AnnexinV/FITC apoptosis detection kit was purchased from BD Biosciences (NJ, USA). Senescence $\beta$ - 
galactosidase (SA- $\beta$-gal) staining kit was purchased from Beyotime (Shanghai, China). All antibodies were obtained from Cell Signaling Technology (MA, USA).

\section{Cell culture}

The human HCC SK-Hep-1, HepG2, and Huh7 cell lines were purchased from Cell Bank of Chinese Academy of Sciences, China. SK-Hep-1 cells were cultured in MEM a containing $10 \%$ FBS at $37^{\circ} \mathrm{C}$ and $5 \%$ $\mathrm{CO}_{2}$. Cells were passaged two or three times per week. HepG2 and Huh7 cells were cultured in DMEM containing $10 \% \mathrm{FBS}$ at $37^{\circ} \mathrm{C}$ and $5 \% \mathrm{CO}_{2}$. Cells were passaged two or three times per week.

\section{Zebrafish}

Wild-type AB strain of zebrafish was purchased from the China Zebrafish Resource Center, Institute of Hydrobiology, China Academy of Science (Wuhan, China) and accredited by the Association for Assessment and Accreditation of Laboratory Animal Care International (SYXK 2012-0171). Larval zebrafish ( $2 \mathrm{dpf}$, days post fertilization) were obtained by natural pair-mating and raised at $28^{\circ} \mathrm{C}$ under a 10/14 h dark/light cycle.

\section{Cell viability assay and morphological observations}

Cells viability was determined by MTT assays. Briefly, cells ( $8 \times 10^{3}$ cells/well) were seeded in 96 -well plates over night, followed by exposure to various concentrations of TB for $24 \mathrm{~h}$ or $48 \mathrm{~h}$. All wells were added ten microliters of MTT reagent $(5.0 \mathrm{mg} / \mathrm{ml})$ and inoculated for $4 \mathrm{~h}$. Afterwards, DMSO was added to dissolve the formazan crystals. Optical density (OD) values at $490 \mathrm{~nm}$ were detected by a microplate reader (Bio-Rad, USA). Inhibitory rate $(\%)=\left[1-\left(\mathrm{OD}_{\mathrm{TB}} / \mathrm{OD}_{\text {control }}\right)\right] \times 100$. The $50 \%$ inhibitory concentrations $\left(\mathrm{IC}_{50}\right)$ of $24 \mathrm{~h}$ and $48 \mathrm{~h}$ were calculated by SPSS Software. And the $\mathrm{IC}_{25}, \mathrm{IC}_{50}$, and $\mathrm{IC}_{75}$ were chosen as the low, medium and high doses of TB for further use.

\section{Animal experiment in zebrafish}

To determine the dose range of TB, larval zebrafish ( $3 \mathrm{dpf}$ ) were treated with various concentrations of TB $(0,6.25,12.5,25,50,100,250,500,1000$, and $2000 \mu \mathrm{g} / \mathrm{ml})$ for $24 \mathrm{~h}$, followed by the observation under a stereoscopic microscope. According to the preliminary studies, no observed adverse effect level (NOAEL) of TB was estimated.

Each larval zebrafish (2 dpf) was microinjected 200 SK-Hep-1 cells labeled with CM-Dil (red fluorescence) into the yolk sac as previously described ${ }^{[37]}$. After $24 \mathrm{~h}, 30$ larval/group were selected under fluorescence microscope and randomly cultured in 6-well plates. The model group, cisplatin $(15 \mu \mathrm{g} / \mathrm{ml})$ group, and TB $(1.7,5.6$, and $16.7 \mu \mathrm{g} / \mathrm{ml})$ group were set up. Zebrafish of each group were observed under fluorescence microscope after $24 \mathrm{~h}$ treatment. The fluorescence intensity (FI) of SK-Hep-1 xenograft tumor was calculated by Image pro plus 6.0 software. The inhibitory rate (IF) was calculated as: Inhibitory rate $(\%)=$ $\left[1-\left(\mathrm{IF}_{\text {treated }} / \mathrm{IF}_{\text {untreated }}\right)\right] \times 100 \%$.

\section{DAPI staining}


The apoptosis of TB-treated SK-Hep-1 cells was detected using DAPI staining. Briefly, SK-Hep-1 cells were treated with TB at 50,100 , and $150 \mu \mathrm{g} / \mathrm{ml}$ for $24 \mathrm{~h}$ respectively. Cells were fixed with $4 \%$ paraformaldehyde for $15 \mathrm{~min}$ and then stained with DAPI (Invitrogen, USA) for 4 min in dark. The apoptotic nuclei of cells were observed under a fluorescence microscope.

\section{Flow cytometry}

The apoptosis of TB-treated SK-Hep-1 cells was also detected using an Annexin-V/PI apoptosis kit. Briefly, TB-treated cells were collected and then labeled with FITC Annexin V and PI according to the manufacturer's protocol. Fluorescence intensity of the cells was measured by a flow cytometry (BD Biosciences, USA). The analysis was replicated thrice and the values of upper right and lower right quadrants of the flow cytometric dot plot were summed to calculate the apoptosis rate (\%) for each TB treatment.

\section{SA- $\beta$-Gal assay}

Senescence of SK-Hep-1 cells was evaluated by SA- $\beta$-gal assay. SK-Hep-1 cells were treated with TB at 50 and $100 \mu \mathrm{g} / \mathrm{ml}$ for $48 \mathrm{~h}$. The cells were washed twice with PBS, and then incubated in fixing solution at room temperature for $15 \mathrm{~min}$. Subsequently, cells were stained with working solution for $24 \mathrm{~h}$. To quantify the percentage of SA- $\beta$-gal-positive cells, 5 digital images were randomly captured by a microscope and the positive cells from each group were counted.

\section{Quantitative real time PCR (qPCR) assay}

As previously described ${ }^{[38]}$, total RNA was extracted using TRIzol reagent and quantified by NanoDrop2000 spectrophotometer (Thermo, USA). Then the RNA was reverse transcribed to CDNA using Primescript RT master mix (TaKaRa, Japan). According to the instructions, mRNA quantity was determined by RT-qPCR system (Applied Biosystems, USA) with SYBR Premix Ex Taq II (Tli RnaseH Plus). The relative mRNA expressions were analyzed by $2^{-\triangle \Delta C T}$ method and $\beta$-Actin was used as the reference gene. Primer sequences are shown in Table 1. 
Table 1

Primer sequences used for QPCR analysis

\begin{tabular}{|c|c|c|}
\hline Gene & Forward primer & Reverse primer \\
\hline$\beta$-actin & 5'-CCCGCGAGTACAACCTTCT-3' & 5'-CGTCATCCATGGCGAACT-3' \\
\hline PUMA & 5'-GACCTCAACGCACAGTACGAG-3' & 5'-AGGAGTCCCATGATGAGATTGT-3' \\
\hline P53 & 5'-TCAACAAGATGTTTTGCCAACTG-3' & 5'-ATGTGCTGTGACTGCTTGTAGATG-3' \\
\hline$P 21$ & 5'-GGCAGACCAGCATGACAGATT-3' & 5'-GCGGATTAGGGCTTCCTCT-3' \\
\hline P16 & 5'-CATGGTGCGCAGGTTCTTG-3' & 5'-CGGGATGTGAACCACGAAA-3' \\
\hline JNK1 & 5'-CCAGGACTGCAGGAACGAGT-3' & 5'-CCACGTTTTCCTTGTAGCCC-3' \\
\hline JNK2 & 5'-ATGACCCCTTACGTGGTGACA-3' & 5'-CATGATGCAACCCACTGACC-3' \\
\hline$I L-8$ & 5'-GAATGGGTTTGCTAGAATGTGATA-3' & 5'-CAGACTAGGGTTGCCAGATTTAAC-3' \\
\hline IL-6 & 5'-TCTCCACAAGCGCCTTCG-3' & 5'-CTCAGGGCTGAGATGCCG-3' \\
\hline GADD45a & 5'-GAGAGCAGAAGACCGAAAGGA-3' & 5'-CACAACACCACGTTATCGGG-3' \\
\hline Bax & 5'-ССTTTTCTACTTTGCCAGCAAAC-3' & 5'-GAGGCCGTCCCAACCAC-3' \\
\hline Bim & 5'-ACCAAACCAAAGCCGTCATCA-3' & 5'-GGAGCCAGTAAACGTATTGGAAG-3' \\
\hline $\operatorname{siP53^{1}}$ & 5'-GACUCCAGUGGUAAUCUAC-3' & 5'-GTAGATTACCACTGGAGTC-3' \\
\hline $\operatorname{siP53}^{2}$ & 5'-GUAGAUUACCACUGGAGUC-3' & 5'-GACTCCAGTGGTAATCTAC-3' \\
\hline siJNK1 & 5'-GGGCCUACAGAGAGCUAGUUCUUAU-3' & 5'-ATAAGAACTAGCTCTCTGTAGGCCC-3' \\
\hline siJNK2 & 5'-CATGAAAGAATGTCCTACСTTCTTT-3' & 5'-AGAAGGTAGGACATTCTTTCATGTT-3' \\
\hline
\end{tabular}

\section{Western blot (WB) analysis}

As previously described ${ }^{[37]}$, total proteins was extracted using RIPA lysis buffer with proteinase inhibitor cocktail (Bimake, USA). And the concentrations of protein were estimated using a Bradford assay kit (Thermo, USA). The proteins were separated by $8-12 \%$ SDS-PAGE and transferred onto a nitrocellulose membrane (Sartorius Stedim, Germany). The membrane was blocked with $5 \%$ BSA at $4^{\circ} \mathrm{C}$ for $2 \mathrm{~h}$, and subsequently incubated at $4^{\circ} \mathrm{C}$ overnight with the following primary antibodies: $\beta$-actin, ATR, phosphoATR, ATM, phospho-ATM, Chk2, phospho-Chk2, p53, phospho-p53, p21, y-H2AX, PARP, c-Casp9, Bax and Bcl-2. After incubation with anti-rabbit or anti-mouse IgG HRP-conjugated antibody, all bands were detected using Western Lightning ${ }^{\circledR}$ Plus ECL (Perkin Elmer, USA). And the results were visualized using Xray film (Kodak, Japan).

\section{Small interfering RNA (siRNA) transfection treatment}


Human p53-targeted (p53-siRNA), JNK1-targeted (JNK1-siRNA), JNK2-targeted (JNK2-siRNA) and negative control (NC-siRNA) siRNAs were designed by GenePharma (Shanghai, China). siRNA transfection was performed on SK-Hep-1 cells using Lipofectamine 2000 (Thermo, USA) according to the manufacturer's instruction. Transfection efficacy was determined via qPCR and WB assays. The siRNA targeting sequences of $P 53, J N K 1$, and JNK2 were shown in Table 1.

\section{Statistical analysis}

The data analyses were performed using SPSS statistics software and were expressed as the mean \pm standard deviation (SD). Statistical significance among different groups were examined using one-way ANOVA followed by Fisher's least significant difference (LSD) comparison. $p<0.05$ was considered statistically significant.

\section{Results}

\section{Anti-proliferative effect of TB}

Anti-proliferative effect of TB on HCC cell lines was determined by cell viability assays and cell morphological observation. TB inhibited proliferation of SK-Hep-1, HepG2 and Huh7 cells from 50 to 600 $\mu \mathrm{g} / \mathrm{ml}$ (Fig. 1a). Given that the inhibitory effect on SK-Hep-1 cells was the strongest, SK-Hep-1 cells were selected for further assays. As depicted in Fig. 1b, TB significantly inhibited cell viability of SK-Hep-1 with the increasing dose and exposure time. And the $\mathrm{IC}_{50}$ values of $24 \mathrm{~h}$ and $48 \mathrm{~h}$ were $100.84 \pm 1.90 \mu \mathrm{g} / \mathrm{ml}$ and $81.25 \pm 0.98 \mu \mathrm{g} / \mathrm{ml}$. According to the $\mathrm{IC}_{50}$ values of $24 \mathrm{~h}$, TB at 50,100 and $150 \mu \mathrm{g} / \mathrm{ml}$ were selected as low, medium and high doses for in vitro assays. Microscopic analyses showed that TB treatment decreased the number of SK-Hep-1 cells and increased the number of the round cells and shrunken cells (Fig. 1c).

\section{Anti-tumor effect of TB in vivo}

The zebrafish mortality and adverse events caused by TB were shown in Fig. 2a. TB obviously induced the adverse events (abnormal roll over) of zebrafish from $25 \mu \mathrm{g} / \mathrm{ml}$ to $500 \mu \mathrm{g} / \mathrm{ml}$. And the first fish death was observed at $500 \mu \mathrm{g} / \mathrm{ml}$ of TB, and all fishes were dead at $1000 \mu \mathrm{g} / \mathrm{ml}$. Based on regression curve, TB's NOAEL was calculated as $16.7 \mu \mathrm{g} / \mathrm{ml}$. And 1.7, 5.6 and $16.7 \mu \mathrm{g} / \mathrm{ml}$ were selected as low, medium and high doses for in vivo experiment. As depicted in Fig. 2b, the HCC xenograft model was established successfully in zebrafish and TB dose-dependently suppressed SK-Hep-1 tumor growth. The inhibitory rates of TB at $1.7,5.6$ and $16.7 \mu \mathrm{g} / \mathrm{ml}$ were $26.15 \%, 32.78 \%$ and $56.30 \%$, respectively. Cis-platinum, one of the first-line of anticancer drugs, was applied as a positive control group. As depicted in Fig. 2c, the inhibitory rate of TB $(16.7 \mu \mathrm{g} / \mathrm{ml})$ was even higher than that of cis-platinum $(15 \mu \mathrm{g} / \mathrm{ml})$.

\section{Pro-apoptotic effect of TB}


DAPI staining was conducted to assess TB-induced apoptosis of SK-Hep-1 cells. As depicted in Fig. 3a, the untreated cells had rounded nuclei with normal blue color, whereas the TB-treated cells had bright blue nuclei and condensed chromatin with apoptotic bodies (indicated by arrows). Similarly, Annexin-V/PI staining also showed significant TB-induced apoptosis on SK-Hep-1 cells (Fig. 3b). The total apoptotic rates (early and late) of TB at 50,100 and $150 \mu \mathrm{g} / \mathrm{ml}$ were $10.40 \%, 34.38 \%$ and $66.04 \%$, respectively. These results suggested that TB dose-dependently induced apoptosis on SK-Hep-1 cells.

\section{Pro-senescent effect of TB}

SA- $\beta$-gal assay was conducted to evaluate the senescence induced by TB on SK-Hep-1 cells. As shown in Fig. 4, the number of SA- $\beta$-Gal-positive cells was obviously increased with TB treatment from 50 to 100 $\mu \mathrm{g} / \mathrm{ml}$, indicating that TB dose-dependently induced senescence on SK-Hep-1.

\section{Molecular actions of TB}

The relative mRNA expression of targeted genes in TB-treated SK-Hep-1 cells was determined by qPCR assay. As depicted in Fig. 5, the expression of $P 53$ was dose-dependently up-regulated by TB at the transcriptional level. TB also increased the expression of down-stream senescent genes $(P 16, P 21, I L-6$ and $I L-8$ ) and apoptotic genes (Bax, Bim and PUMA).

The protein expression of targeted molecules in TB-treated SK-Hep-1 cells was determined by WB. A strong phosphorylation of ATM, ATR, Chk2, and p53 was detected in TB-treated SK-Hep-1 cells (Fig. 6), indicating the activation of p53 signaling pathway. From low to high doses, TB obviously increased the expression of downstream apoptotic markers ( $\mathrm{Y}-\mathrm{H} 2 \mathrm{AX}, \mathrm{c}-\mathrm{PARP}, \mathrm{c}-\mathrm{Casp} 9$ and Bax ) with down-regulation of anti-apoptotic protein Bcl-2. The regulatory effects of TB on these genes and protein were dosedependent.

\section{Verification of p53-mediated mechanism of TB}

p53-siRNA was applied to determine whether p53 signaling mediates the senescence and apoptosis in TB-treated SK-Hep-1 cells. The transfection efficacy was confirmed by qPCR and WB assays (Fig. 7c and d). Cell viability assay and DAPI staining showed that p53-siRNA significantly counteracted the TBmediated anti-proliferative and pro-apoptotic effect on SK-Hep-1 cells (Fig. 7a and b). qPCR assays revealed that p53-siRNA significantly suppressed the expression of senescent genes ( $P 21, G A D D 45 a$ and $I L-6)$ and antagonized the regulation of TB on these senescent genes and apoptotic genes (Bax and Bim) (Fig. 7c). WB assays revealed that p53-siRNA notably decreased the expression of p21 and Bax, increased the expression of $\mathrm{Bcl}-2$, and counteracted the regulation of TB on these proteins.

Our previous studies have shown that TB induced apoptosis on p53-mut HCC cells via activation of JNK signaling ${ }^{[39]}$. Thus, JNK-siRNA was applied to verify the involvement of JNK in the action mechanism of TB. As shown in Fig. 7e, TB obviously up-regulated the expression of JNK1 and JNK2 and JNK-siRNA substantially reversed the regulation of TB on these genes as well as on the senescent (GADD45a and IL- 
8) and apoptotic genes (Bax and PUMA). The above results indicated that $\mathrm{p} 53$ signaling and JNK participated in the TB-induced cellular senescence and apoptosis of SK-Hep-1 cells.

\section{Discussion}

TB is known to improve the lipid metabolism and reduce the cholesterol level of liver, indicating its beneficial effect on liver ${ }^{[40]}$. Our study revealed that TB exhibited significant inhibitory effects on HCC cell lines (SK-Hep-1, HepG2, and Huh7), in which the effect on p53-WT SK-Hep-1 cells was the strongest. Accordingly, we conducted the present study to determine the anti-HCC efficacy and explore the mechanism of TB on SK-Hep-1 cell line. Our findings demonstrated that TB significantly suppressed SKHep-1 tumor growth in xenograft zebrafish and induced cellular senescence and apoptosis of SK-Hep-1 cells through activation of ATM-Chk2-p53 cascade with bypass regulation of JNK. The innovation points of this study are as follows: 1) demonstration of the inhibitory efficacy of TB on p53-WT HCC cells (SKHep-1);2) clarification of the action mechanism of TB through cell apoptosis and cellular senescence; and 3) determination of TB囚s molecular mechanism via ATM-Chk2-p53 signaling pathway with JNK bypass regulation.

Cellular senescence is a cell state characterized by permanent cell-cycle arrest with widespread changes in chromatin organization and gene expression ${ }^{[41,42]}$. p53 and pRb are critical transcriptional regulators in cellular senescence. p21 is one of the most important targets of p53 transcriptional activity in senescent process, whereas $\mathrm{p} 16$ is a positive upstream regulator of $\mathrm{pRB}^{[43]}$. A vital feature of senescent cells is the secretion of senescent associated secretory phenotype (SASP), such as pro-inflammatory cytokines and chemokines, growth factors, etc. ${ }^{[44,45]}$. Except for p53, p16, and p21, IL6 and IL8 are also the central components of SASP and act as important markers of cellular senescence ${ }^{[46,47]}$. Our data showed that TB significantly induced senescent phenotype (SA-ß-gal positive) of SK-Hep-1 cells with upregulation of all the above senescent markers ( $P 53, P 16, P 21, I L-6$ and $I L-8)$ (Fig. 4 and 5), indicating that TB induced cellular senescence to suppress SK-Hep-1 cells through p53-related mechanism. Some chemotherapeutics possess anti-cancer efficacy via inducing cellular senescence, such as Palbociclib, a specific CDK4/6 inhibitor, which was approved in 2015 for clinical treatment of advanced breast cancer [48].

Besides the cellular senescence, TB meanwhile induced apoptosis of SK-Hep-1 cells. The pro-apoptotic p53 signaling pathway was activated by TB through activation of p-ATM, p-ATR, $\mathrm{y}-\mathrm{H} 2 \mathrm{AX}, \mathrm{p}-\mathrm{Chk} 2$, and pp53 (Fig. 6). ATM and ATR are initiating kinases of DNA damage response (DDR) cascade, while $Y-H 2 A X$ serves as a sensitive biomarker for DNA damage during DNA double-strand breaks (DSBs) ${ }^{[49,50]}$. In response to the DNA DSBs, ATM phosphorylates itself at Ser1981 to activate extensive substrates to mediate cell cycle checkpoint control, DNA repair or apoptosis ${ }^{[51]}$. The serine/threonine kinase Chk2 is another component of DDR, which requires ATM-activated phosphorylation at several residues including Thr68 ${ }^{[52]}$. Activated Chk2 phosphorylates $p 53$, enhancing its stability and activity to induce apoptosis through Bcl-2 and caspase-dependent manners ${ }^{[53]}$. Therefore, TB induced apoptosis of SK-Hep-1 cells 
with DNA DSBs through ATM-Chk2-p53 signaling pathway. Subsequently, the downstream apoptotic proteins (Bax, c-Casp9 and c-PARP) and genes (PUMA, Bim and Bax) were activated, resulting in the mitochondrial pathway of apoptosis (Fig. 8). Casp9 is the initiating caspase associated with the mitochondrial apoptosis ${ }^{[54]}$. Once activated, Casp9 cleaves and activates downstream effectors to cleave PARP, which promotes cellular disassembly and serves as a hallmark of apoptosis ${ }^{[55,56]}$.

Previous report has shown that p53 signaling plays a critical role in modulating cellular responses to DNA damage, leading to irreversible cellular senescence and apoptosis ${ }^{[57]}$. This study verified the p53 signaling-mediated pro-apoptotic and pro-senescent mechanism of TB by using p53-siRNA (Fig. 7). In our previous study, TB induced apoptosis in p53-mut Huh7 cells via activation of JNK signaling pathway, indicating that JNK might also participate into the action mechanism of TB on HCC cells ${ }^{[58]}$. Correspondingly, we revealed that JNK was a bypass regulator involved in the mechanism of TB (Fig. 7e), suggesting a multi-target mechanism of TB on both ATM-Chk2-p53 and JNK signaling (Fig. 8). Further studies are needed to explore the possible cross-talk between p53 and JNK signalings in response to the anti-HCC efficacy of TB.

\section{Declarations}

\section{Ethics approval and consent to participate}

Not applicable.

\section{Consent for publication}

Not applicable.

\section{Availability of data and materials}

All data generated or analyzed during this study are included in this published article and its supplementary information files.

\section{Funding}

This work was supported by National Natural Science Foundation of China (Grant No. 811873049 and 82074464), Zhejiang Natural Science Foundation Young Scholars (Grant No. LQ20H270009), Zhejiang Traditional Chinese Medical Science Foundation (Grant No. 2020ZA039, LY18H270016 and LY18H270004), Zhejiang Provincial key Research and development program (2021C03046), Science and Technology Development Project of Hangzhou (Grant No. 2020ZDSJ0900), and Zhejiang Provincial Key Construction University Superiority Characteristic Discipline (Traditional Chinese Medicine and Traditional Chinese Pharmacology) Opening Foundation of China (Grant No. ZYX2018006, ZYXYB2019001, ZYXZD2019001, and ZYAOXYB2019010).

\section{Author's Contributions}


JAX carried out the experiments and wrote the manuscript; BY and XJX performed animal experiments; QY, XQD, and QD provided reagents and funding support; JZ analyzed the data; LTS and LZ designed and supervised the experiments; ZSD and TE participated in the research design. All authors have given approval to the final version of the manuscript.

\section{Competing Interests}

Author Jin Zhang was employed by the company Theabio Co., Ltd. The remaining authors declare that the research was conducted in the absence of any commercial or financial relationships that could be construed as a potential conflict of interest.

\section{Acknowledgment}

Not applicable.

\section{References}

1. Bray F, Ferlay J, Soerjomataram I, Siegel RL, Torre LA, Jemal A: Global cancer statistics 2018 : GLOBOCAN estimates of incidence and mortality worldwide for 36 cancers in 185 countries. $C A$ Cancer J Clin 2018, 68(6):394-424.

2. Petrick JL, Florio AA, Znaor A, Ruggieri D, Laversanne M, Alvarez CS, Ferlay J, Valery PC, Bray F, McGlynn KA: International trends in hepatocellular carcinoma incidence, 1978-2012. Int J Cancer 2020, 147(2):317-330.

3. Akinyemiju T, Abera S, Ahmed M, Alam N, Alemayohu MA, Allen C, Al-Raddadi R, Alvis-Guzman N, Amoako Y, Artaman A et al: The Burden of Primary Liver Cancer and Underlying Etiologies From 1990 to 2015 at the Global, Regional, and National Level: Results From the Global Burden of Disease Study 2015. JAMA Oncol 2017, 3(12):1683-1691.

4. Singh S, Singh PP, Roberts LR, Sanchez W: Chemopreventive strategies in hepatocellular carcinoma. Nat Rev Gastroenterol Hepatol 2014, 11(1):45-54.

5. McGlynn KA, Petrick JL, El-Serag HB: Epidemiology of Hepatocellular Carcinoma. Hepatology 2021, 73 Suppl 1.

6. El-Serag HB: Hepatocellular carcinoma. N Engl J Med 2011, 365(12):1118-1127.

7. Dutta R, Mahato RI: Recent advances in hepatocellular carcinoma therapy. Pharmacol Ther 2017, 173:106-117.

8. Cheng A-L, Kang Y-K, Chen Z, Tsao C-J, Qin S, Kim JS, Luo R, Feng J, Ye S, Yang T-S et al: Efficacy and safety of sorafenib in patients in the Asia-Pacific region with advanced hepatocellular carcinoma: a phase III randomised, double-blind, placebo-controlled trial. Lancet Oncol 2009, 10(1):25-34.

9. Bruix J, Takayama T, Mazzaferro V, Chau G-Y, Yang J, Kudo M, Cai J, Poon RT, Han K-H, Tak WY et al: Adjuvant sorafenib for hepatocellular carcinoma after resection or ablation (STORM): a phase 3, 
randomised, double-blind, placebo-controlled trial. Lancet Oncol 2015, 16(13):1344-1354.

10. Rebouissou S, Nault J-C: Advances in molecular classification and precision oncology in hepatocellular carcinoma. J Hepatol 2020, 72(2):215-229.

11. Ozturk M, Arslan-Ergul A, Bagislar S, Senturk S, Yuzugullu H: Senescence and immortality in hepatocellular carcinoma. Cancer Lett 2009, 286(1):103-113.

12. Nault JC, Mallet M, Pilati C, Calderaro J, Bioulac-Sage P, Laurent C, Laurent A, Cherqui D, Balabaud C, Zucman-Rossi $\mathrm{J}$ et al: High frequency of telomerase reverse-transcriptase promoter somatic mutations in hepatocellular carcinoma and preneoplastic lesions. Nat Commun 2013, 4:2218.

13. Pilati C, Letouzé E, Nault J-C, Imbeaud S, Boulai A, Calderaro J, Poussin K, Franconi A, Couchy G, Morcrette $\mathrm{G}$ et al: Genomic profiling of hepatocellular adenomas reveals recurrent FRK-activating mutations and the mechanisms of malignant transformation. Cancer Cell 2014, 25(4):428-441.

14. de La Coste A, Romagnolo B, Billuart P, Renard CA, Buendia MA, Soubrane O, Fabre M, Chelly J, Beldjord C, Kahn A et al: Somatic mutations of the beta-catenin gene are frequent in mouse and human hepatocellular carcinomas. Proc Natl Acad Sci U S A 1998, 95(15):8847-8851.

15. Audard V, Grimber G, Elie C, Radenen B, Audebourg A, Letourneur F, Soubrane O, Vacher-Lavenu MC, Perret $\mathrm{C}$, Cavard $\mathrm{C}$ et al: Cholestasis is a marker for hepatocellular carcinomas displaying betacatenin mutations. J Pathol 2007, 212(3):345-352.

16. Hsu IC, Metcalf RA, Sun T, Welsh JA, Wang NJ, Harris CC: Mutational hotspot in the p53 gene in human hepatocellular carcinomas. Nature 1991, 350(6317):427-428.

17. Totoki Y, Tatsuno K, Covington KR, Ueda H, Creighton CJ, Kato M, Tsuji S, Donehower LA, Slagle BL, Nakamura $\mathrm{H}$ et al: Trans-ancestry mutational landscape of hepatocellular carcinoma genomes. Nat Genet 2014, 46(12):1267-1273.

18. Bressac B, Kew M, Wands J, Ozturk M: Selective $G$ to $T$ mutations of $p 53$ gene in hepatocellular carcinoma from southern Africa. Nature 1991, 350(6317):429-431.

19. Kruiswijk F, Labuschagne CF, Vousden KH: p53 in survival, death and metabolic health: a lifeguard with a licence to kill. Nat Rev Mol Cell Biol 2015, 16(7):393-405.

20. Bouaoun L, Sonkin D, Ardin M, Hollstein M, Byrnes G, Zavadil J, Olivier M: TP53 Variations in Human Cancers: New Lessons from the IARC TP53 Database and Genomics Data. Hum Mutat 2016, 37(9):865-876.

21. Wasylishen AR, Lozano G: Attenuating the p53 Pathway in Human Cancers: Many Means to the Same End. Cold Spring Harb Perspect Med 2016, 6(8).

22. Wurz RP, Cee VJ: Targeted Degradation of MDM2 as a New Approach to Improve the Efficacy of MDM2-p53 Inhibitors. J Med Chem 2019, 62(2):445-447.

23. Green JA, Von Euler M, Abrahmsen LB: Restoration of conformation of mutant p53. Ann Oncol2018, 29(5):1325-1328.

24. Bykov VJN, Eriksson SE, Bianchi J, Wiman KG: Targeting mutant p53 for efficient cancer therapy. Nat Rev Cancer 2018, 18(2). 
25. Duffy MJ, Synnott NC, O'Grady S, Crown J: Targeting p53 for the treatment of cancer. Semin Cancer Biol 2020.

26. Reis B, Jukofsky L, Chen G, Martinelli G, Zhong H, So WV, Dickinson MJ, Drummond M, Assouline S, Hashemyan $\mathrm{M}$ et al: Acute myeloid leukemia patients' clinical response to idasanutlin (RG7388) is associated with pre-treatment MDM2 protein expression in leukemic blasts. Haematologica 2016, 101(5):e185-e188.

27. Ding Q, Zhang Z, Liu J-J, Jiang N, Zhang J, Ross TM, Chu X-J, Bartkovitz D, Podlaski F, Janson C et al: Discovery of RG7388, a potent and selective p53-MDM2 inhibitor in clinical development. $J$ Med Chem 2013, 56(14):5979-5983.

28. Di Lorenzo A, Curti V, Tenore GC, Nabavi SM, Daglia M: Effects of Tea and Coffee Consumption on Cardiovascular Diseases and Relative Risk Factors: An Update. Curr Pharm Des 2017, 23(17):24742487.

29. Ramadan G, El-Beih NM, Talaat RM, Abd El-Ghffar EA: Anti-inflammatory activity of green versus black tea aqueous extract in a rat model of human rheumatoid arthritis. Int J Rheum Dis 2017, 20(2):203-213.

30. Santamarina AB, Carvalho-Silva M, Gomes LM, Okuda MH, Santana AA, Streck EL, Seelaender M, do Nascimento CMO, Ribeiro EB, Lira FS et al: Decaffeinated green tea extract rich in epigallocatechin-3gallate prevents fatty liver disease by increased activities of mitochondrial respiratory chain complexes in diet-induced obesity mice. J Nutr Biochem 2015, 26(11):1348-1356.

31. Suzuki T, Pervin M, Goto S, Isemura M, Nakamura Y: Beneficial Effects of Tea and the Green Tea Catechin Epigallocatechin-3-gallate on Obesity. Molecules 2016, 21(10).

32. Kim TL, Jeong GH, Yang JW, Lee KH, Kronbichler A, van der Vliet HJ, Grosso G, Galvano F, Aune D, Kim JY et al: Tea Consumption and Risk of Cancer: An Umbrella Review and Meta-Analysis of Observational Studies. Adv Nutr 2020, 11(6):1437-1452.

33. Liu J, Liu S, Zhou H, Hanson T, Yang L, Chen Z, Zhou M: Association of green tea consumption with mortality from all-cause, cardiovascular disease and cancer in a Chinese cohort of 165,000 adult men. Eur J Epidemiol 2016, 31(9):853-865.

34. Huang F, Zheng X, Ma X, Jiang R, Zhou W, Zhou S, Zhang Y, Lei S, Wang S, Kuang J et al: Theabrownin from Pu-erh tea attenuates hypercholesterolemia via modulation of gut microbiota and bile acid metabolism. Nat Commun 2019, 10(1):4971.

35. Yue S, Zhao D, Peng C, Tan C, Wang Q, Gong J: Effects of theabrownin on serum metabolites and gut microbiome in rats with a high-sugar diet. Food Funct 2019, 10(11):7063-7080.

36. Wu E, Zhang T, Tan C, Peng C, Chisti Y, Wang Q, Gong J: Theabrownin from Pu-erh tea together with swinging exercise synergistically ameliorates obesity and insulin resistance in rats. Eur J Nutr 2020, 59(5):1937-1950.

37. Jin W, Zhou L, Yan B, Yan L, Liu F, Tong P, Yu W, Dong X, Xie L, Zhang J et al: Theabrownin triggers DNA damage to suppress human osteosarcoma U2OS cells by activating p53 signalling pathway. $J$ Cell Mol Med 2018, 22(9):4423-4436. 
38. Wu F, Zhou L, Jin W, Yang W, Wang Y, Yan B, Du W, Zhang Q, Zhang L, Guo Y et al: Anti-Proliferative and Apoptosis-Inducing Effect of Theabrownin against Non-small Cell Lung Adenocarcinoma A549 Cells. Front Pharmaco/ 2016, 7:465.

39. Xu J, Yan B, Zhang L, Zhou L, Zhang J, Yu W, Dong X, Yao L, Shan L: Theabrownin Induces Apoptosis and Tumor Inhibition of Hepatocellular Carcinoma Huh7 Cells Through ASK1-JNK-c-Jun Pathway. Onco Targets Ther 2020, 13:8977-8987.

40. Huang F, Zheng X, Ma X, Jiang R, Zhou W, Zhou S, Zhang Y, Lei S, Wang S, Kuang J et al: Theabrownin from Pu-erh tea attenuates hypercholesterolemia via modulation of gut microbiota and bile acid metabolism. Nat Commun 2019, 10(1):4971.

41. Kirkland JL, Tchkonia T: Cellular Senescence: A Translational Perspective. EBioMedicine 2017, 21:2128.

42. Campisi J: Aging, cellular senescence, and cancer. Annu Rev Physiol 2013, 75:685-705.

43. Martínez-Zamudio RI, Robinson L, Roux P-F, Bischof O: SnapShot: Cellular Senescence Pathways. Cell 2017, 170(4).

44. Salama R, Sadaie M, Hoare M, Narita M: Cellular senescence and its effector programs. Genes Dev 2014, 28(2).

45. Coppé J-P, Desprez P-Y, Krtolica A, Campisi J: The senescence-associated secretory phenotype: the dark side of tumor suppression. Annu Rev Pathol 2010, 5.

46. Kuilman T, Peeper DS: Senescence-messaging secretome: SMS-ing cellular stress. Nat Rev Cancer 2009, 9(2):81-94.

47. Tchkonia T, Zhu Y, van Deursen J, Campisi J, Kirkland JL: Cellular senescence and the senescent secretory phenotype: therapeutic opportunities. J Clin Invest 2013, 123(3):966-972.

48. Orjalo AV, Bhaumik D, Gengler BK, Scott GK, Campisi J: Cell surface-bound IL-1alpha is an upstream regulator of the senescence-associated IL-6/IL-8 cytokine network. Proc Natl Acad Sci U S A 2009, 106(40):17031-17036.

49. Turner NC, Ro J, André F, Loi S, Verma S, Iwata H, Harbeck N, Loibl S, Huang Bartlett C, Zhang K et al: Palbociclib in Hormone-Receptor-Positive Advanced Breast Cancer. N Engl J Med 2015, 373(3):209219.

50. Lee JH, Paull TT: Activation and regulation of ATM kinase activity in response to DNA double-strand breaks. Oncogene 2007, 26(56):7741-7748.

51. Blackford AN, Jackson SP: ATM, ATR, and DNA-PK: The Trinity at the Heart of the DNA Damage Response. Mol Cell 2017, 66(6):801-817.

52. Roos WP, Kaina B: DNA damage-induced cell death by apoptosis. Trends Mol Med 2006, 12(9):440450.

53. Matsuoka S, Rotman G, Ogawa A, Shiloh Y, Tamai K, Elledge SJ: Ataxia telangiectasia-mutated phosphorylates Chk2 in vivo and in vitro. Proc Natl Acad Sci U S A 2000, 97(19):10389-10394. 
54. Zannini L, Delia D, Buscemi G: CHK2 kinase in the DNA damage response and beyond. J Mol Cell Biol 2014, 6(6):442-457.

55. Allan LA, Clarke PR: Apoptosis and autophagy: Regulation of caspase-9 by phosphorylation. FEBS J 2009, 276(21):6063-6073.

56. D'Amours D, Sallmann FR, Dixit VM, Poirier GG: Gain-of-function of poly(ADP-ribose) polymerase-1 upon cleavage by apoptotic proteases: implications for apoptosis. J Cell Sci 2001, 114(Pt 20):37713778.

57. Kaufmann SH, Desnoyers S, Ottaviano Y, Davidson NE, Poirier GG: Specific proteolytic cleavage of poly(ADP-ribose) polymerase: an early marker of chemotherapy-induced apoptosis. Cancer Res 1993, 53(17):3976-3985.

58. Haronikova L, Olivares-Illana V, Wang L, Karakostis K, Chen S, Fåhraeus R: The p53 mRNA: an integral part of the cellular stress response. Nucleic Acids Res 2019, 47(7):3257-3271.

\section{Figures}


a
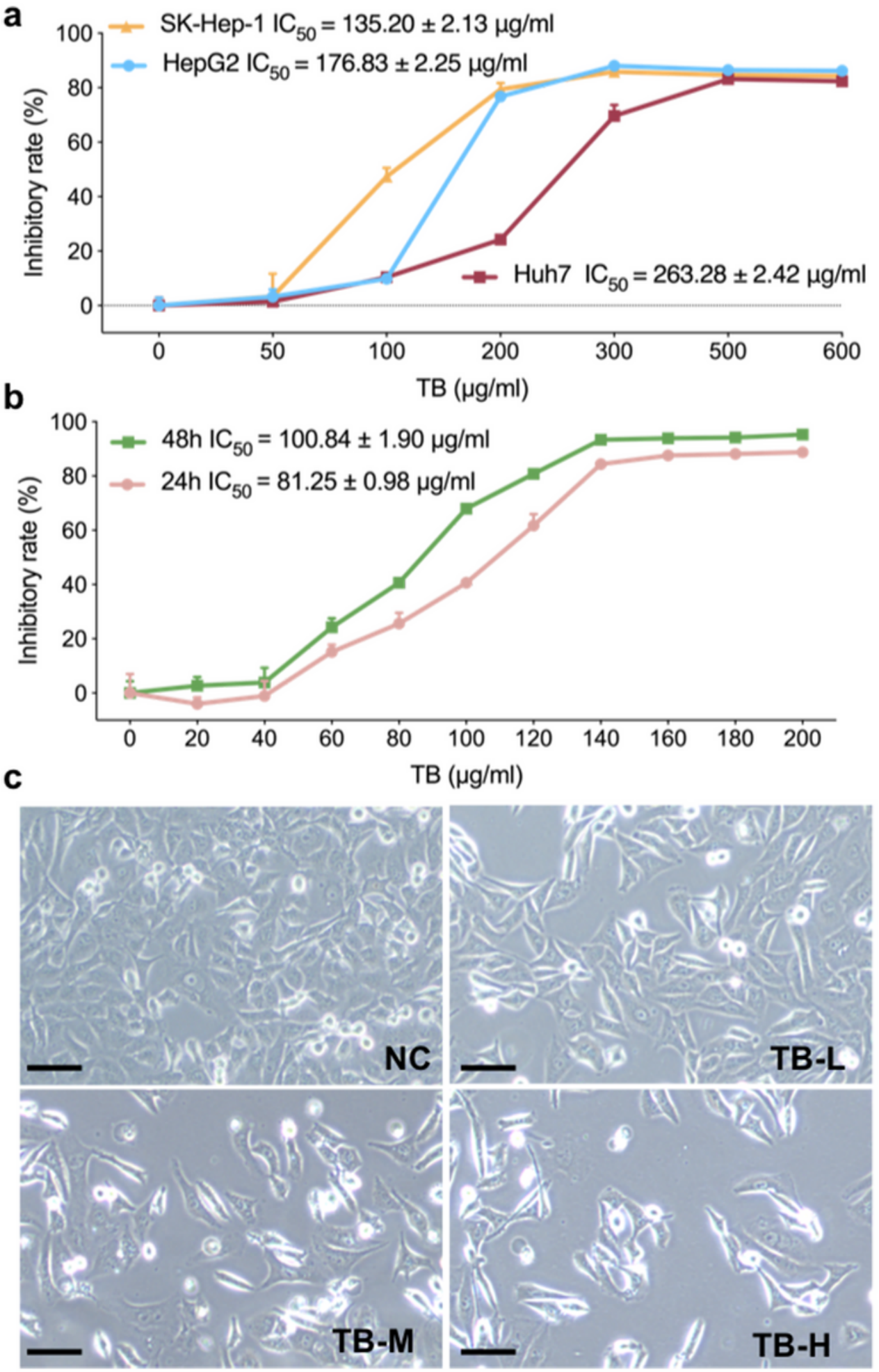

\section{Figure 1}

a: Inhibitory rate of TB on SK-Hep-1, HepG2, and Huh7 cells at $24 \mathrm{~h}$. b: IC50 of TB on SK-Hep-1 cells at 24 $\mathrm{h}$ and $48 \mathrm{~h}$. c: Morphological observation (light microscope) of SK-Hep1 cells with TB treatment for $24 \mathrm{~h}$. Scale bar: $100 \mu \mathrm{m}$.

左 


\section{Figure 2}

a: The mortality and adverse events of larval zebrafish with TB treatment. b: Observation of SK-Hep-1 xenograft zebrafish with cis-platin or TB treatment. c: Data of fluorescence intensity and inhibitory effect of cis-platin or TB. The fluorescent area (red) represents the HCC tumor mass. Values were presented as the mean \pm SD $(n=30) .{ }^{*} p<0.01$ vs. model $(0 \mu \mathrm{g} / \mathrm{ml})$.
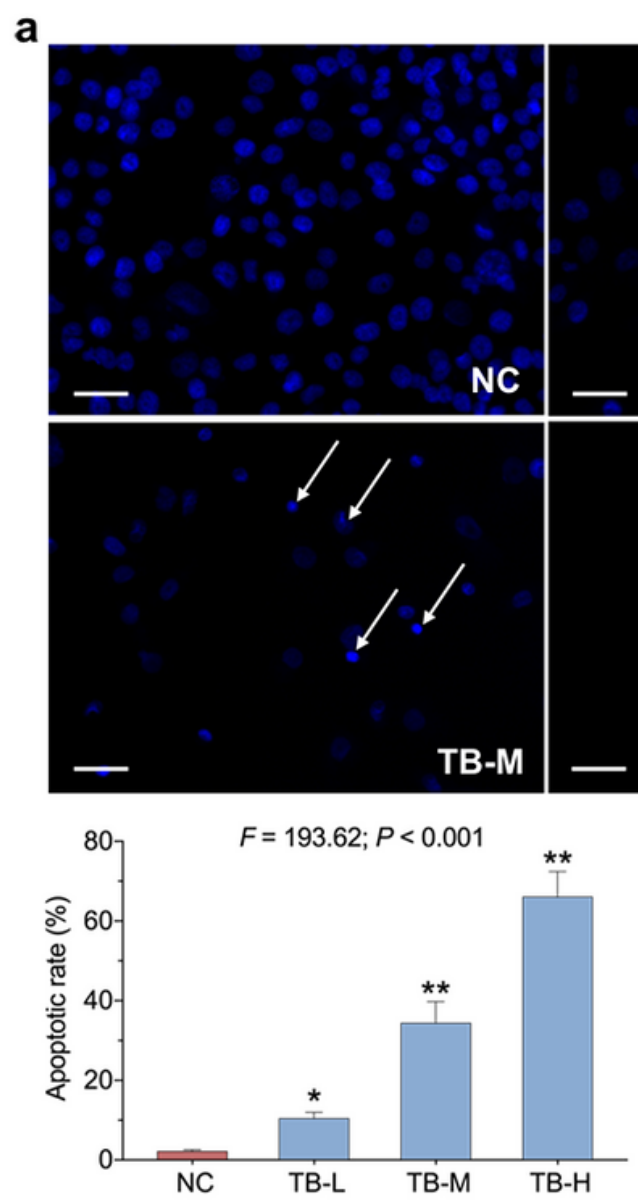
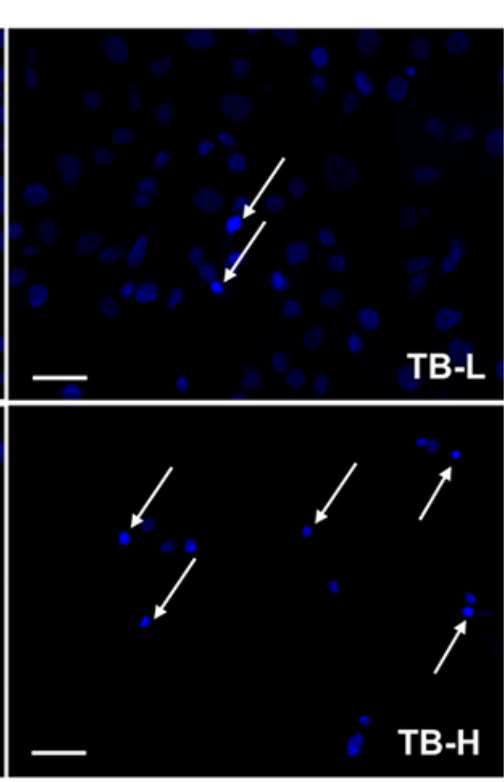

b

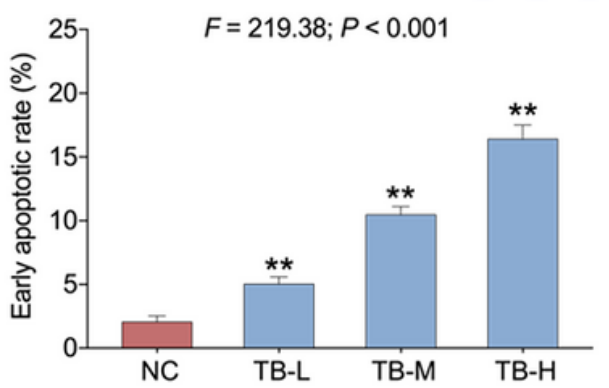

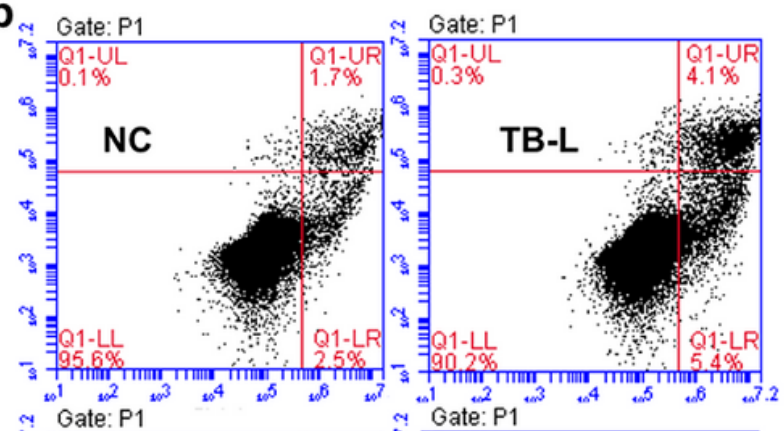
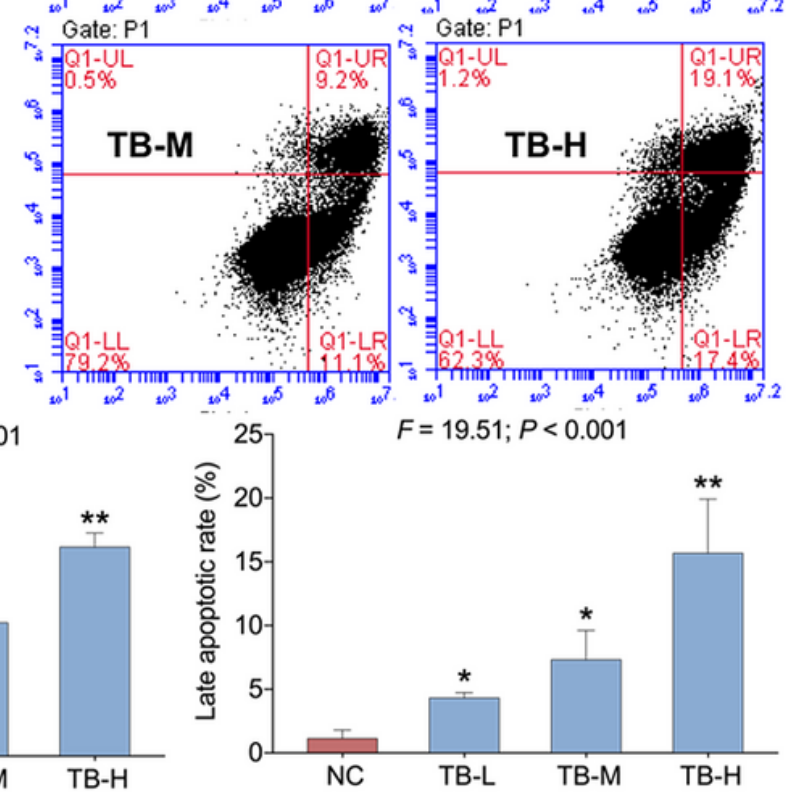

\section{Figure 3}

a: Representative images of DAPI staining of SK-Hep-1 cells with TB treatment for $24 \mathrm{~h}$. Scale bar: $50 \mu \mathrm{m}$. b: Flow cytometry analysis on SK-Hep-1 cell apoptosis with TB treatment for $24 \mathrm{~h}$. Values were presented as the mean $\pm S D(n=3) .{ }^{*} p<0.05$ and ${ }^{* *} p<0.01$ vs. normal control.

\section{Figure 4}

Representative images of SA- $\beta$-gal staining of SK-Hep-1 cells with TB treatment for 48 h. Scale bar: 200 $\mu \mathrm{m}$. Values were presented as the mean $\pm \mathrm{SD}(\mathrm{n}=5)$. ${ }^{\star *} \mathrm{p}<0.01$. vs normal control. 

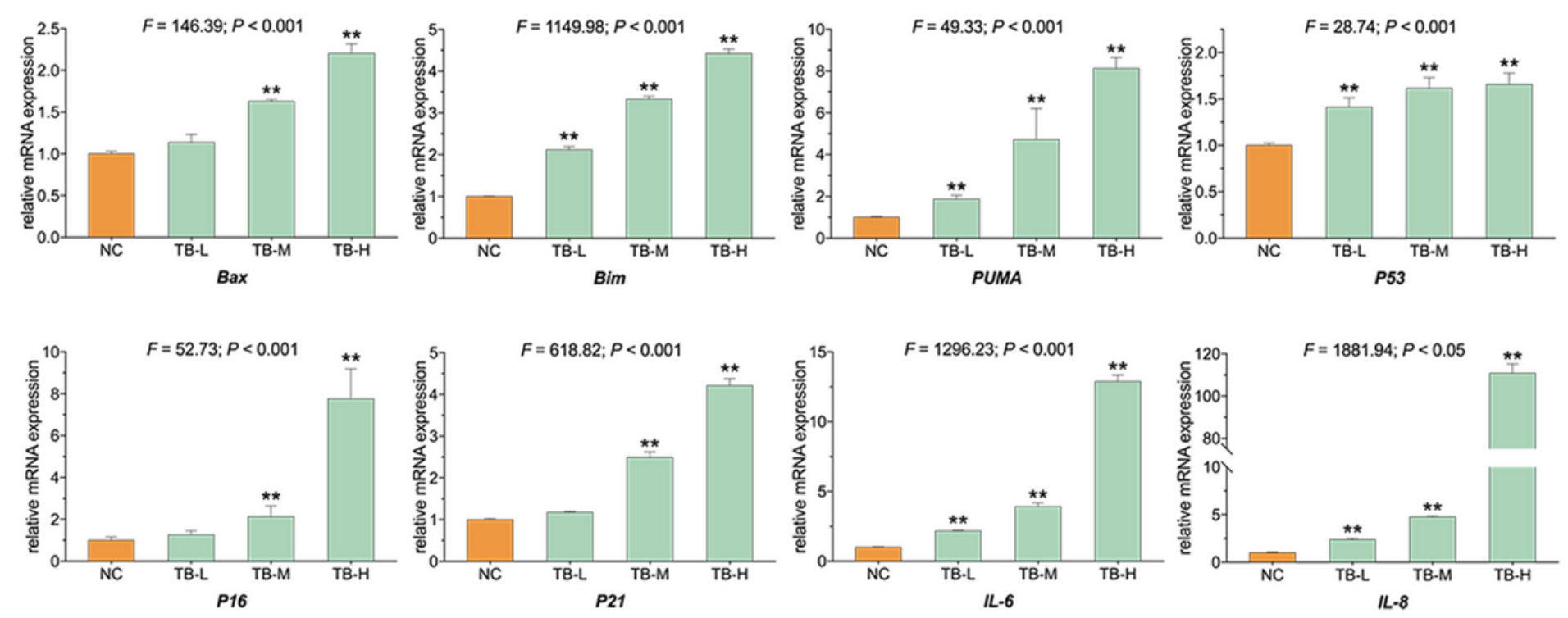

\section{Figure 5}

Relative mRNA expression of target genes in SK-Hep-1 cells with TB treatment for $24 \mathrm{~h}$. Values are presented as mean $\pm S D(n=3)$. ${ }^{*} p<0.01$ vs. normal control.

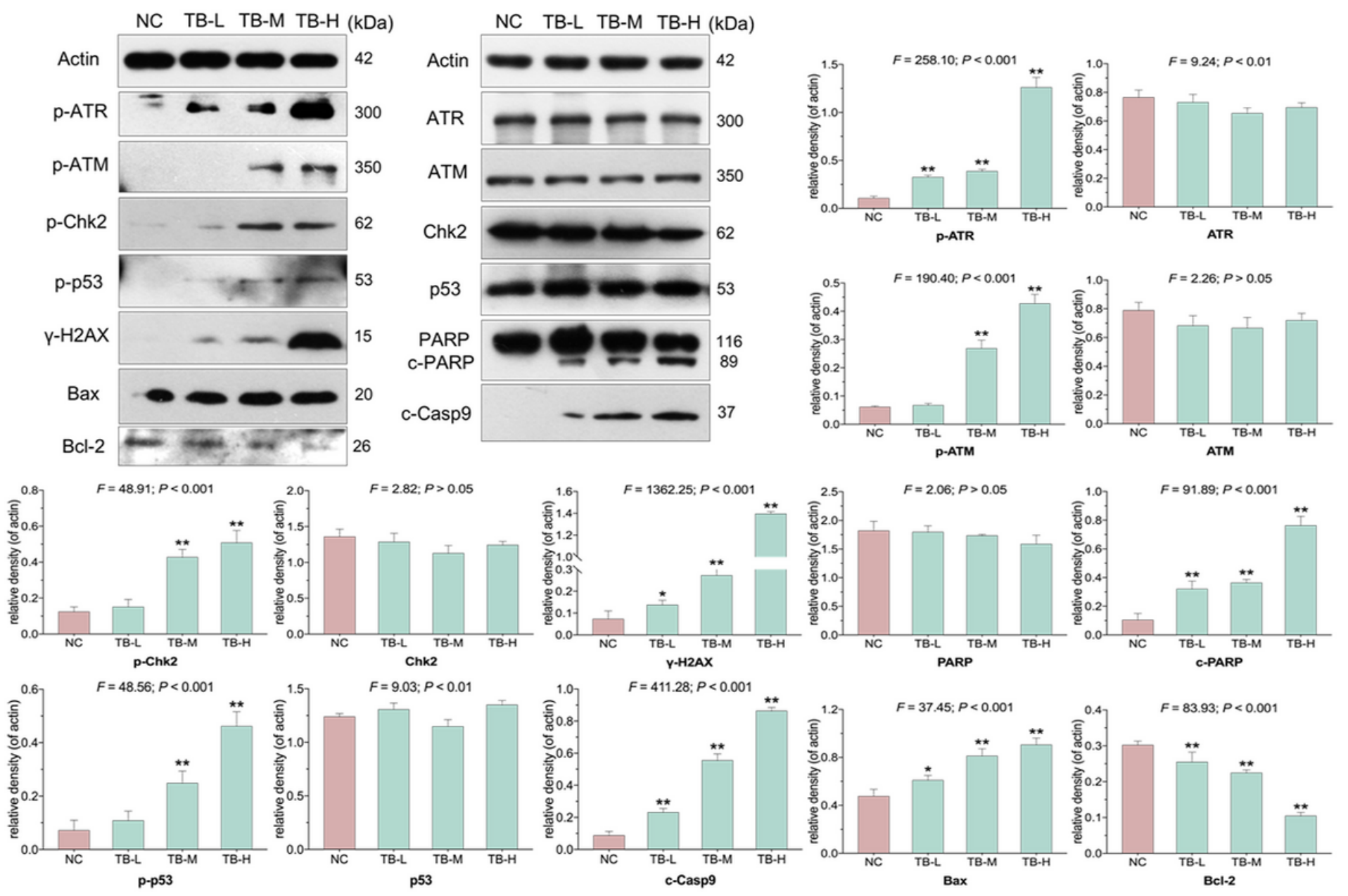

\section{Figure 6}


Expression and phosphorylation of targeted proteins in SK-Hep-1 cells with TB treatment for $24 \mathrm{~h}$. Values represent mean $\pm S D(n=3)$. ${ }^{*} p<0.05$ and ${ }^{* *} p<0.01$ vs. normal control.

a
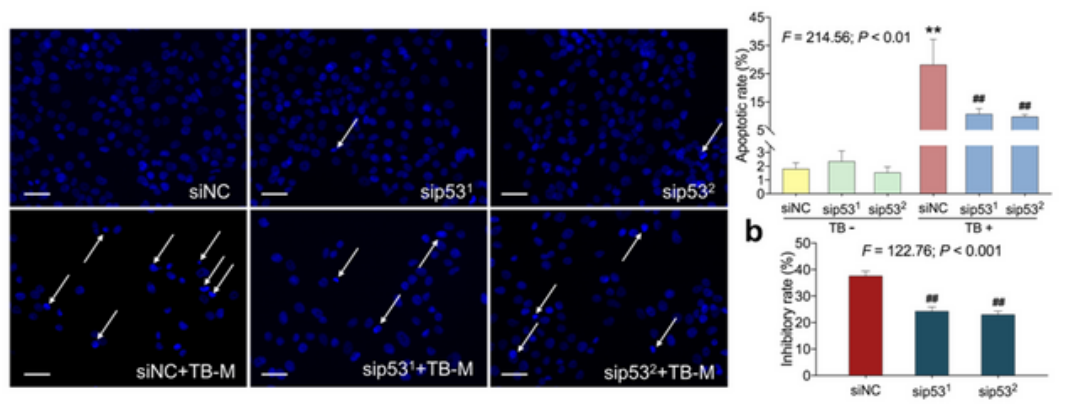

C
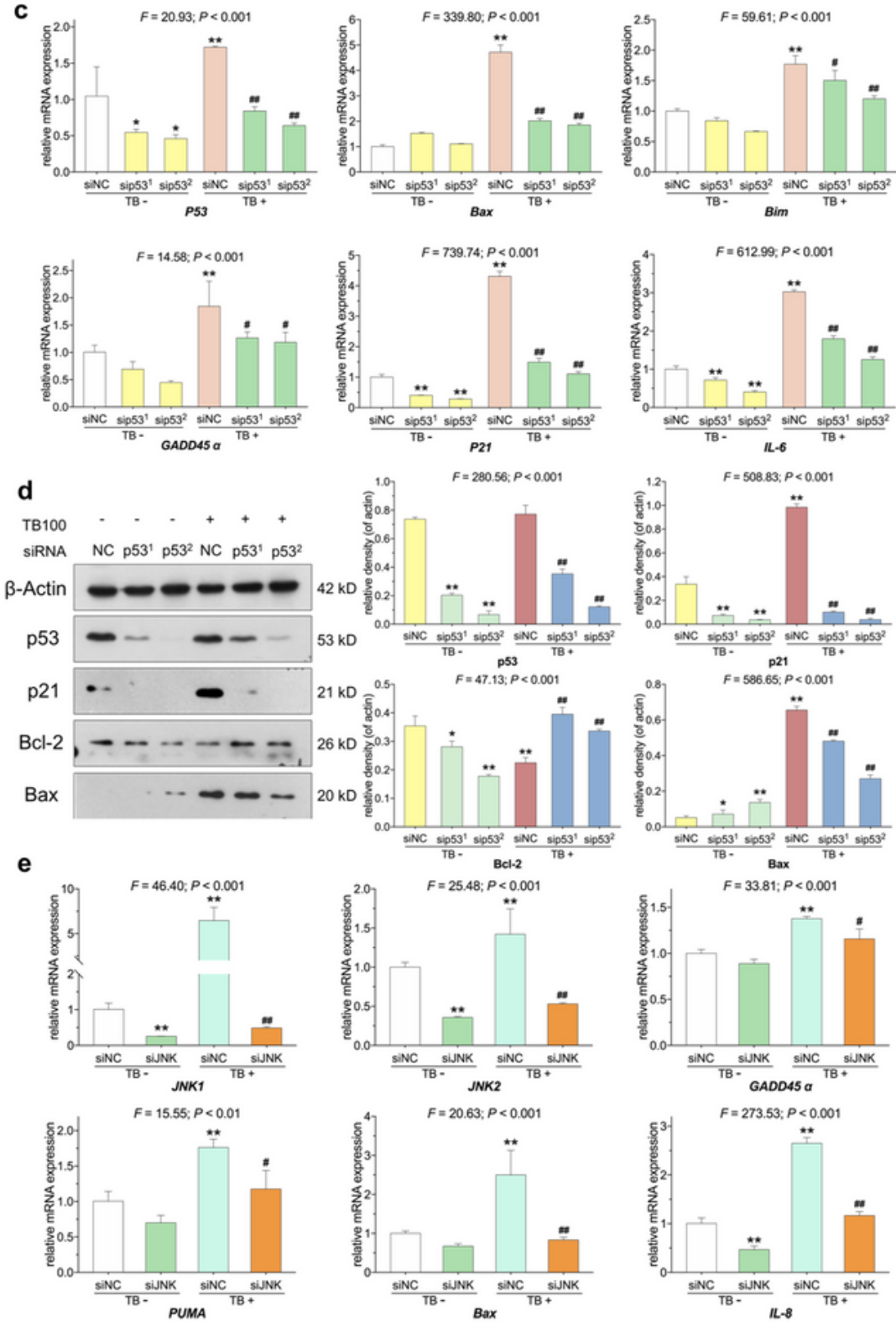

Figure 7

a: Apoptotic morphology of SK-Hep-1 cells with p53-siRNA and TB $(100 \mu \mathrm{g} / \mathrm{ml})$ treatment by DAPI staining. Scale bar: $50 \mu \mathrm{m}$. Values are presented as mean $\pm S D(n=5) .{ }^{\star \star} p<0.01$ vs siNC group, \#\#p < 0.01 vs siNC group plus TB treatment. b: Inhibitory rate of TB $(100 \mu \mathrm{g} / \mathrm{ml})$ with nontargeting control 
siRNA or p53-siRNA treatments on SK-Hep-1 cells at 24h. Values were presented as the mean \pm SD $(n=$ 5). \#\#p < 0.01 vs siNC group plus TB treatment. c: Relative mRNA expression of SK-Hep-1 cells with p53siRNA and TB $(100 \mu \mathrm{g} / \mathrm{ml})$ treatments for $24 \mathrm{~h}$. Values are presented as mean $\pm S D(n=3)$. ${ }^{*} p<0.05$ and ${ }^{* *} \mathrm{p}<0.01$ vs siNC group, $\# p<0.05$ and \#\#p $<0.01$ vs siNC group plus TB treatment. $d$ : Relative protein expression of SK-Hep-1 cells with p53-siRNA and TB $(100 \mu \mathrm{g} / \mathrm{ml})$ treatments for $24 \mathrm{~h}$. Values are presented as mean $\pm S D(n=3)$. ${ }^{*} p<0.05$ and ${ }^{* *} p<0.01$ vs siNC group, $\# \# p<0.01$ vs siNC group plus TB treatment. e: Relative mRNA expression of SK-Hep-1 cells with JNK-siRNA and TB $(100 \mu \mathrm{g} / \mathrm{ml})$ treatments for $24 \mathrm{~h}$. Values are presented as mean $\pm S D(n=3)$. ${ }^{*} p<0.05$ and ${ }^{*} p<0.01$ vs siNC group, $\# p<0.05$ and \#\#p $<0.01$ vs siNC group plus TB treatment. siNC: nontargeting control siRNA-treated group; sip53: p53-siRNA-treated group; siJNK: JNK-siRNA-treated group.

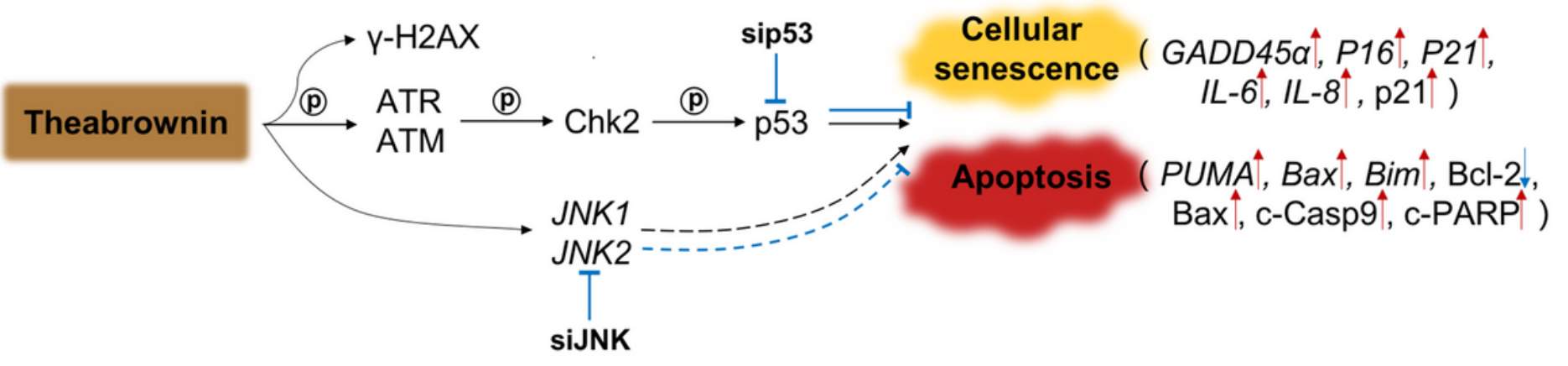

Figure 8

Schematic diagram of the mechanism of TB on SK-Hep-1 cells. 